\title{
Original
}

\section{Therapeutic Effect of an Immunomodulator on Pancreatic Endocrine Secretion Disorder and Insulitis in an Animal Model of Autoimmune Pancreatitis}

\author{
Yuta Mitsui ${ }^{1)}$, Tadashi Honma ${ }^{1)}$, Yoshiki Sato ${ }^{1)}$, \\ Akira YAMAMIYA $^{1)}$, Yu IshiI ${ }^{1)}$, Tomohiro NOMOTO ${ }^{1)}$, \\ Takahisa YAmAZAKI $^{1)}$, Akihiro YukawA ${ }^{1)}$, Katsuya KitamurA ${ }^{1)}$, \\ Tsunao ImamurA ${ }^{1,3)}$, Akitoshi Ikegami ${ }^{1)}$, Shigeki TanakA ${ }^{1,2)}$ \\ and Hitoshi YoshidA ${ }^{* 1)}$
}

\begin{abstract}
Adrenocortical hormones are effective in many, but not all, cases of autoimmune pancreatitis (AIP). While effective treatment for refractory and recurrent cases of AIP has not been established, immunomodulators are sometimes used. We examined the therapeutic effect of the immunomodulator FK506 against AIP using an animal model: aly/aly male mice. Mice were divided into three groups based on FK506 dose : $1 \mathrm{mg} / \mathrm{kg}, 2 \mathrm{mg} / \mathrm{kg}$, and non-administration (pancreatitis) groups. Pancreatic exocrine gland injury was regarded as pancreatitis and pancreatic endocrine injury was regarded as insulitis. Histological evaluation of pancreatic tissue at 16 and 24 weeks of age was performed quantitatively using ImageJ software, and the three groups were compared. The pancreatitis group developed pancreatitis at 24 weeks of age, but onset of pancreatitis was suppressed in the $1 \mathrm{mg}$ group. However, pancreatitis development was not suppressed in the $2 \mathrm{mg}$ group, and pancreatitis developed from as early as 16 weeks of age. In the pancreatitis group, insulitis resulted in morphological changes such as shrinkage of pancreatic islets of Langerhans as inflammatory cell infiltration into pancreatic acinar cells became stronger. No significant difference was observed between the $1 \mathrm{mg}$ group and the pancreatitis group in the islet area but, in the $2 \mathrm{mg}$ group, there was significant reduction in area compared to the pancreatitis group and the $1 \mathrm{mg}$ group. Although administration of FK506 at a low dose had an effect of suppressing the onset of pancreatitis, administration at a higher dose appeared to exacerbate pancreatitis.
\end{abstract}

Key words : autoimmune pancreatitis, aly mouse, FK506, pancreatitis, insulitis

\section{Background}

Case reports of pancreatitis that suggest involvement of autoimmune mechanisms as a cause have been published since the 1960s. In Japan during recent years, the concept of autoimmune

1) Division of Gastroenterology, Department of Medicine, Showa University School of Medicine, 1-5-8 Hatanodai, Shinagawa-ku, Tokyo 142-8666, Japan.

2) Department of Health and Medicine, Tokyo Ariake University of Health Sciences.

3) Department of Gastroenterology, Toranomon Hospital.

* To whom corresponding should be addressed. 
pancreatitis (AIP) as a disease has been proposed, and the pathophysiology of AIP is gradually being elucidated. AIP is pancreatitis with hypergammaglobulinemia, high levels of hyper-IgG/ IgG4 or other findings that suggest involvement of autoimmune mechanisms.

In many cases of AIP, adrenocortical hormone therapy is effective, but refractory and recurrent AIP cases are also common. Although immunomodulatory drugs are considered to be effective for refractory and recurrent cases, and are administered occasionally, their efficacy has not yet been assessed.

We have conducted and reported histological and immunological studies of pancreatic and extra-pancreatic lesion in autoimmune pancreatitis (AIP) using aly mice as an animal model of autoimmune pancreatitis. Pancreatic lesions were analyzed as exocrine disorder and endocrine disorder, and histologically analyzed as pancreatitis and insulitis, respectively. In aly mice, findings of pancreatitis emerged from 16 weeks of age, and insulitis occurred somewhat later from 24 weeks of age and more weight loss was observed as pancreatitis became more severe.

In this article, we describe histological and immunological studies of pancreatic and extrapancreatic lesions in AIP, using aly mice as an AIP model, and our evaluation of the effects of two doses of the immunomodulatory drug FK506 (common name: tacrolimus) on these lesions.

To evaluate the therapeutic effect of FK506, pancreatic lesions were analyzed as exocrine disorder and endocrine disorder, and histologically analyzed as pancreatitis and insulitis, respectively. In addition, changes in pancreatic exocrine secretory cells, CD8-positive $\mathrm{T}$ cells, CD4-positive $\mathrm{T}$ cells, CD11b-positive cells, Foxp3 and IFN- $\gamma \mathrm{R} \alpha$ were histologically assessed.

\section{Methods}

\section{Housing and treatment of mice, and autopsy procedure}

Eight-week-old aly/aly male mice were allocated to three groups: two administration (treatment) groups and one non-administration (pancreatitis) group. Each group consisted of 12 mice. The mice had been raised in a 12-hour light/dark cycle at room temperature $\left(23^{\circ} \mathrm{C}\right)$, with freely available high-pressure steam sterilized diet and chlorinated drinking water that had been boiled.

The mice in the treatment groups were intraperitoneally administered $1 \mathrm{mg} / \mathrm{kg}$ or $2 \mathrm{mg} / \mathrm{kg}$ of FK506 (Abcam, Cambridge, UK) every 2 days with a 27G needle. The mice in the pancreatitis group were intraperitoneally administered $100 \mathrm{mM}$ dimethylsulfoxide (DMSO) diluted with distilled water in the same manner as treatment group. The volume of DMSO administration was $0.6 \mathrm{ml}$, based on an estimated body weight of $35 \mathrm{~g}$.

At 16 and 24 weeks of age, blood was collected from the heart of each mouse. Once exsanguination was completed and cardiac arrest was confirmed, samples of pancreatic, splenic and submaxillary gland tissue were collected. Mice were carefully observed during and after this procedure to minimize their pain and determine an appropriate time for euthanasia. Euthanasia was conducted with $\mathrm{NO}_{2}$ or pentobarbital overdose (dose : $50 \mathrm{mg} / \mathrm{kg}$; working concentration : $64.8 \mathrm{mg} / \mathrm{ml} ; 27 \mathrm{G}$ needle). Organ excision was performed after confirmation of death. For ethical reasons, we performed painful procedures in as short a period as possible. We observed the condition of the mice at least once a week and tried to perform dissection at the time when 
weight loss (more than 20\% from the start of the experiment), worsened coat condition and abnormal behavior (such as abnormal walking) were seen. Autopsy was conducted after blood collection and blood removal by the axillary artery or ventricular puncture, which was performed under anesthesia induced by intraperitoneal administration of pentobarbital to minimize pain.

\section{Preparation of FK506 (tacrolimus hydrate) solution}

Based on an estimated mouse body weight of $35 \mathrm{~g}$ and an FK506 dose of $2 \mathrm{mg} / \mathrm{kg}$, a solution of $0.07 \mathrm{mg} / \mathrm{ml} \mathrm{FK506} \mathrm{was} \mathrm{prepared} \mathrm{by} \mathrm{dissolving} 2 \mathrm{mg}$ of FK506 in $50 \mu \mathrm{l}$ of DMSO and diluting this with $57 \mathrm{ml}$ of physiological saline. However, precipitation of FK506 was observed, and FK506 did not dissolve even when further dilution in DMSO was performed. FK506 was found to be soluble in distilled water. We sought the highest concentration without observing any precipitation, found that $0.07 \mathrm{mg}$ per $0.6 \mathrm{ml}$ was the upper limit, and made the solution with that concentration. We dissolved $10 \mathrm{mg}$ of FK506 in $122 \mu \mathrm{l}$ of $100 \mathrm{mM}$ DMSO and diluted it with $85.7 \mathrm{ml}$ of distilled water to prepare a $0.14 \mathrm{mg} / \mathrm{ml}$ solution for $2 \mathrm{mg} / \mathrm{kg}$ dosing (2 $\mathrm{mg}$ group). The solution was further diluted to $0.07 \mathrm{mg} / \mathrm{ml}$ solution for $1 \mathrm{mg} / \mathrm{kg}$ dosing (1 mg group).

\section{Characteristics of the aly mouse}

The aly (alymphoplasia) mouse is a model of immunodeficiency in which lymph nodes and Peyer plates are congenitally lost throughout the whole body, and in-vivo lymphocyte function is lacking despite the presence of $\mathrm{T}$ cells and $\mathrm{B}$ cells. These abnormalities are caused by an autosomal recessive mutation on a single gene. Histologically, lymphocyte-mediated inflammatory cell infiltration occurs in the pancreas, and pancreatic acinar cell disorder is observed. It is presumed that autoimmune abnormality is involved, so we used the aly mouse as a model of spontaneous pancreatitis. In this study, we used homozygous aly/aly male mice (CLEA Japan, Tokyo, Japan) as a model of AIP. Various immunodeficiencies occur in homozygous aly/aly mice, whereas heterozygous aly mice $($ aly $/+$ ) do not have an immunodeficiency. In our study, findings of pancreatitis in the aly mice emerged from 16 weeks of age, and insulitis occurred from 24 weeks of age.

\section{Hematoxylin-eosin staining}

At 16 and 24 weeks of age, we conducted autopsy in four mice from each of the three groups. Pancreatic tissue was fixed in formalin, and this was followed by hematoxylin-eosin (HE) staining. The excised pancreas was fixed with $10 \%$ formaldehyde, embedded in paraffin, sectioned, and stained with HE. Images were taken at random in four fields of view, around vessels and ducts of pancreatic tissue in which there was strong infiltration by inflammatory cells. To avoid bias, the numbers of inflammatory cells were counted using open-source software (ImageJ, National Institutes of Health, Bethesda, USA). Objectively quantified data were analyzed and statistically examined as an index of inflammation. 
5. Immunofluorescent staining (insulin, amylase, glucagon, CD4, CD8, CD11b, Foxp3 and IFN- $\gamma R \alpha$ cell staining) and evaluation of endocrine function

Infiltrated inflammatory cells were analyzed with enzyme antibody method. Antibodies used were Insulin and Amylase (Bioss Antibodies, Woburn, MA, USA), CD4, CD8 and CD11b (Novusbio Biologicals, Littleton, CO, USA), IFN- $\gamma$ Ra (Bioworld Technology, St. Louis Park, MN, USA), Foxp3 and CD45R (GeneTex, Irvine, CA, USA).

Insulin staining was conducted to quantify the area of the pancreas head and evaluate endocrine ( $\beta$ cell) function. This was done using 24-week-old mice. In each group, relatively large pancreatic islets stained for insulin were randomly photographed for each slide. Ten pancreatic islets were chosen for each slide. The area of the pancreatic islets was measured using ImageJ, and the area size (pixel count) was used as an index of endocrine function.

\section{Statistical analysis}

Statistical analysis was conducted using JMP ${ }^{\circledR}$ Pro 13.0.0 (SAS, Institute, Cary, NC, USA). Results for the three groups were compared by using the Kruskal-Wallis test to examine differences between groups. For the significant differences between groups, a multiple comparison test was conducted using the Steel-Dwass test. $\mathrm{P}<0.05$ was considered statistically significant.

\section{Results}

\section{Body weight changes}

Body weight of the aly mice increased in each group on a weekly basis up to 24 weeks of age, but was suppressed in the drug administration groups. The weight gain in the pancreatitis group was significantly higher than in the $1 \mathrm{mg}$ and $2 \mathrm{mg}$ groups $(\mathrm{P}=0.0054$ and $\mathrm{P}=0.0027$, respectively), but there was no significant difference in body weight gain between the $1 \mathrm{mg}$ and $2 \mathrm{mg}$ groups $(\mathrm{P}=0.1565)$. In each group, there was no significant change in body weight gain from 18 to 24 weeks of age (Fig. 1).

\section{Evaluation of inflammatory cell infiltration using $H E$ staining}

In the pancreatitis group, strong inflammatory cell infiltration was observed around the pancreatic duct from 24 weeks of age. Inflammatory cell infiltration was observed from 16 weeks of age in the $2 \mathrm{mg}$ group. In the $1 \mathrm{mg}$ group, inflammation was suppressed at both 16 and 24 weeks of age. According to quantification of the inflammatory cells using ImageJ, the number of inflammatory cells at the age of 16 weeks was significantly lower in the $1 \mathrm{mg}$ group compared with the $2 \mathrm{mg}$ group $(\mathrm{P}=0.0004)$, and significantly lower in the pancreatitis group compared with the $2 \mathrm{mg}$ group $(\mathrm{P}<0.001)$, but there was no significant difference between the $1 \mathrm{mg}$ group and the pancreatitis group $(\mathrm{P}=0.8849)$. At 24 weeks of age, inflammation was significantly lower in the $1 \mathrm{mg}$ group compared with the pancreatitis group $(\mathrm{P}<0.001)$ and compared with the $2 \mathrm{mg}$ group $(\mathrm{P}=0.016)$. The difference between the pancreatitis group and the $2 \mathrm{mg}$ group was not significant $(\mathrm{P}=0.818)$. On histopathological evaluation, pancreatitis suppression was apparent in the $1 \mathrm{mg}$ group. However, inhibitory effects were not obtained in the $2 \mathrm{mg}$ group, 


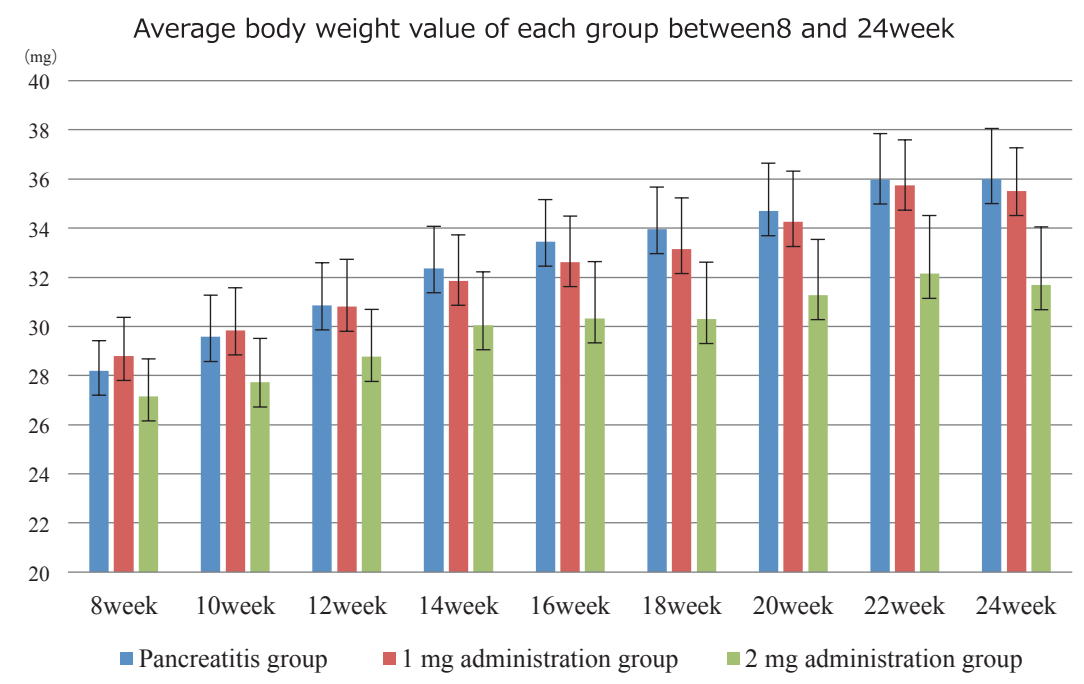

Fig. 1. Average body weight of each group from 8 to 24 weeks of age. Increases in body weight occurred in all groups from 8 to 16 weeks of age, but increases were smaller in the $1 \mathrm{mg}$ and $2 \mathrm{mg}$ groups than in the pancreatitis group. From 18 to 24 weeks, there were no differences in body weight gain between groups.

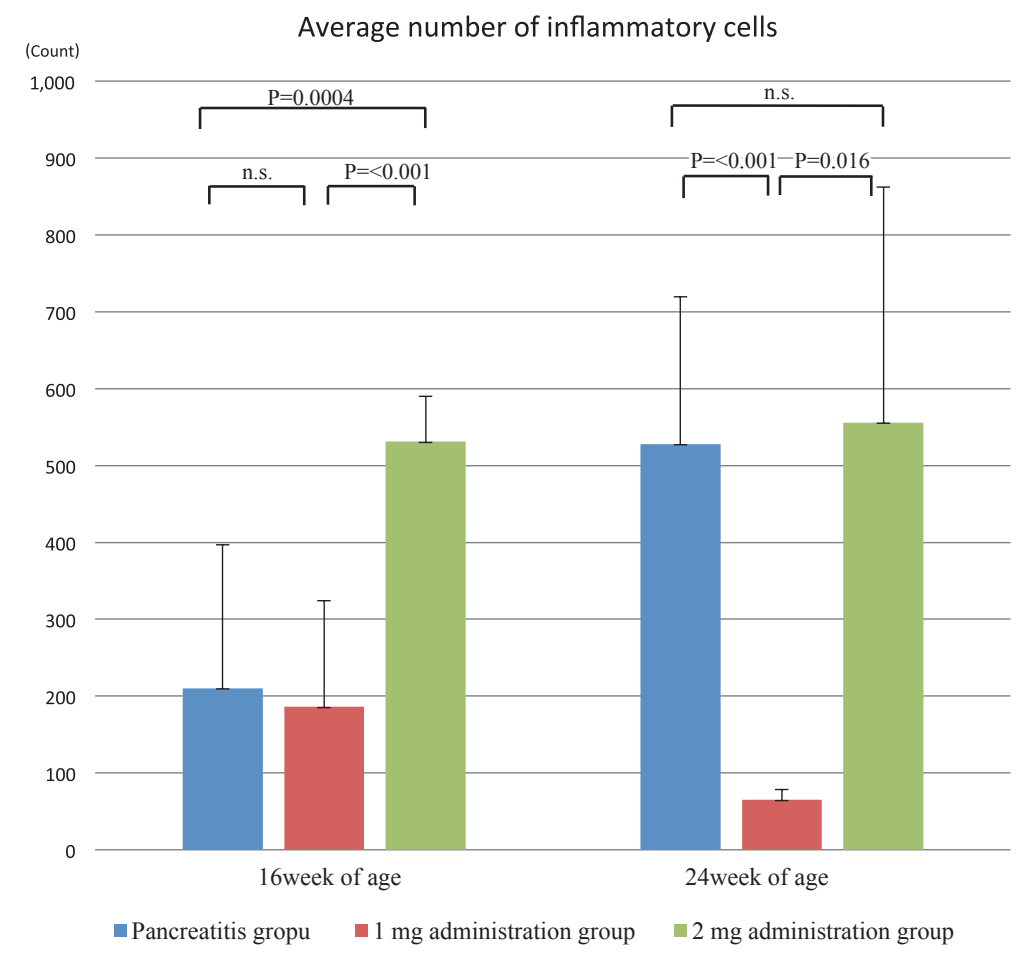

Fig. 2. Average number of inflammatory cells in each group at 16 and 24 weeks of age. At 16 weeks of age, the inflammatory cell infiltration around the duct in the $2 \mathrm{mg}$ group was significantly stronger compared with that in the pancreatitis and $1 \mathrm{mg}$ group. There was no significant difference between the pancreatitis group and $1 \mathrm{mg}$ group. Compared with the pancreatitis group and $2 \mathrm{mg}$ group at 24 weeks of age, inflammatory cell infiltration was suppressed significantly in the $1 \mathrm{mg}$ group. There was no significant difference in inflammatory cell infiltration between the pancreatitis group and the $2 \mathrm{mg}$ group. 


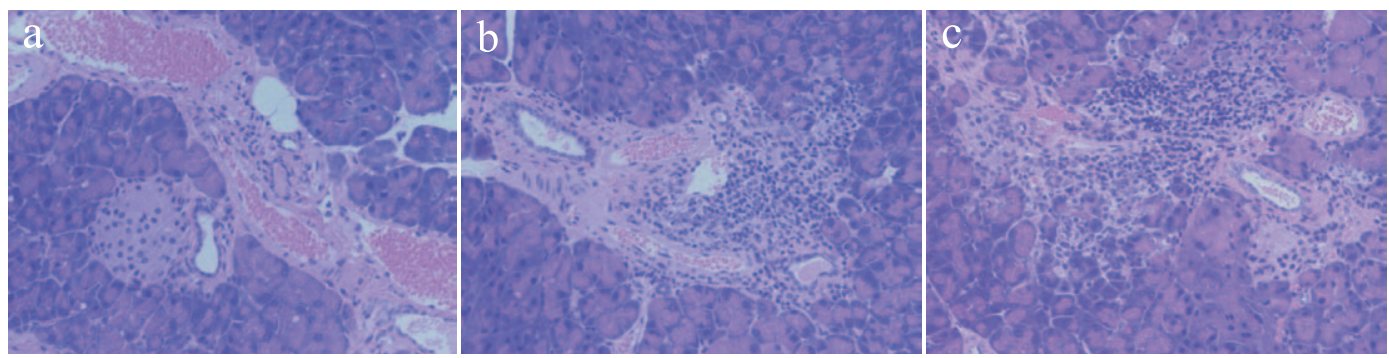

Fig. 3. HE staining at 16 weeks of age. Inflammatory cell infiltration around the duct was suppressed in the $1 \mathrm{mg}$ group. Inflammatory cell infiltration was observed around the duct in the $2 \mathrm{mg}$ group, and was observed partially around the duct in the pancreatitis group.

a : 16 weeks of age, $1 \mathrm{mg}$ group, $\mathrm{HE}$ staining, $\times 200$

$\mathrm{b}: 16$ weeks of age, $2 \mathrm{mg}$ group, $\mathrm{HE}$ staining, $\times 200$

c: 16 weeks of age, pancreatitis group, HE staining, $\times 200$
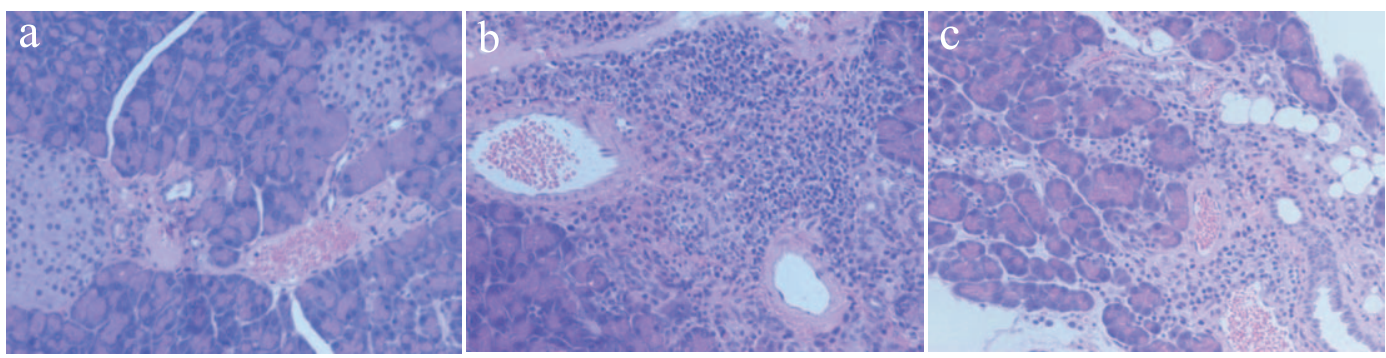

Fig. 4. HE staining at 24 weeks of age. Inflammatory cell infiltration was inhibited in the $1 \mathrm{mg}$ group and observed around the duct in the $2 \mathrm{mg}$ and pancreatitis groups.

a : 24 weeks of age, $1 \mathrm{mg}$ group, $\mathrm{HE}$ staining, $\times 200$

$\mathrm{b}: 24$ weeks of age, $2 \mathrm{mg}$ group, HE staining, $\times 200$

c : 24 weeks of age, pancreatitis group, HE staining, $\times 200$

and inflammatory cell infiltration was observed from 16 weeks, which was earlier than in the pancreatitis group (Figs. 2-4).

\section{Immunostaining}

\section{i) Insulin}

Islet $\beta$ cells were stained using insulin staining, and the morphology of islets and infiltrating inflammatory cells were compared. Inflammatory cell infiltration was observed in pancreatic islets of Langerhans in areas where inflammatory cell infiltration was strong, and morphological changes such as size reduction and spherical shape collapse were observed in islets of Langerhans.

In areas with less inflammatory cell infiltration, the shape of pancreatic islets of Langerhans was maintained. In the pancreatitis group and the $2 \mathrm{mg}$ group, in which pancreatitic inflammation was strong, islet shrinkage and morphological changes were frequently observed. However, in the $1 \mathrm{mg}$ group, the shape of pancreatic islets was maintained as compared with the other groups (Fig. 5).

ii) Glucagon

With glucagon staining, $\alpha$ cells at the periphery of pancreatic islets of Langerhans were 


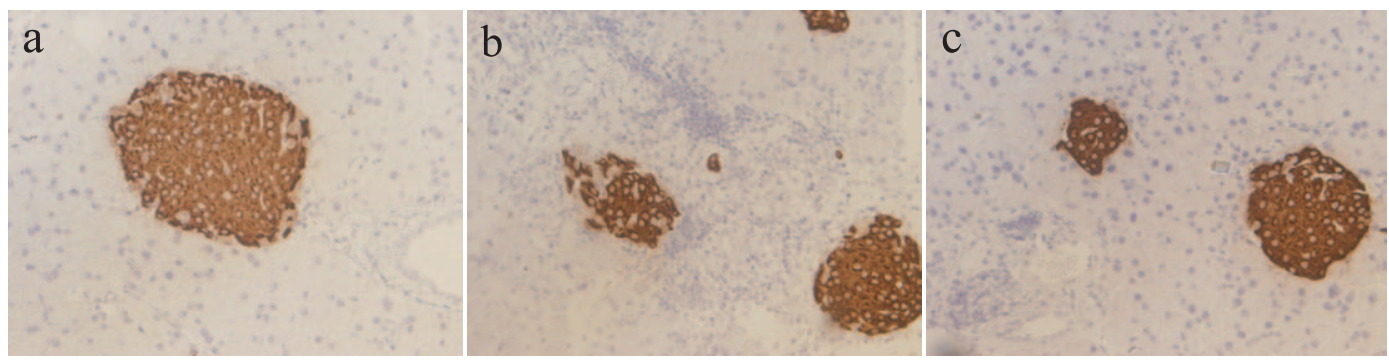

Fig. 5. Insulin staining at 24 weeks of age. In the pancreatitis group and $2 \mathrm{mg}$ group, islet shrinkage and morphological changes were observed.

a : 24 weeks of age, $1 \mathrm{mg}$ group, insulin staining, $\times 200$

$\mathrm{b}: 24$ weeks of age, $2 \mathrm{mg}$ group, insulin staining, $\times 200$

c: 24 weeks of age, pancreatitis group, insulin staining, $\times 200$
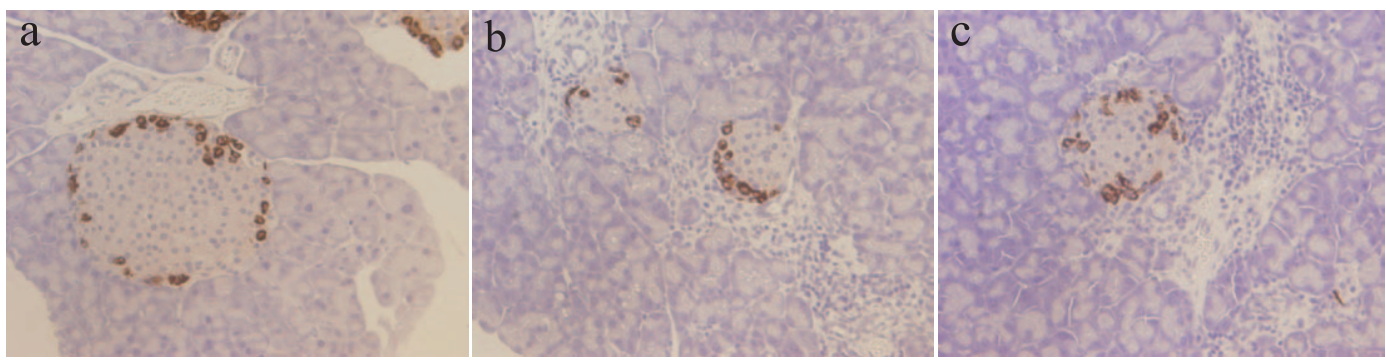

Fig. 6. Glucagon staining at 24 weeks of age. $\alpha$ cells on the periphery of the pancreatic islet were stained. Peripheral $\alpha$ cells were also maintained even in reduced pancreatic islets.

a : 24 weeks of age, $1 \mathrm{mg}$ group, glucagon staining, $\times 200$

$\mathrm{b}: 24$ weeks of age, $2 \mathrm{mg}$ group, glucagon staining, $\times 200$

c: 24 weeks of age, pancreatitis group, glucagon staining, $\times 200$

stained. The morphology of $\alpha$ cells was maintained in pancreatic islets of Langerhans which showed insulitis was occurring. As with insulin staining, the shape of the pancreatic islet was maintained in the $1 \mathrm{mg}$ group compared with the pancreatitis group and $2 \mathrm{mg}$ group with strong inflammatory cell infiltration (Fig. 6).

iii) $\mathrm{CD} 4$ and $\mathrm{CD} 8$

With CD4 and CD8 staining, cell infiltration of CD4- and CD8-positive T lymphocytes was observed at the sites where inflammatory cell infiltration was observed, and CD4-positive $\mathrm{T}$ lymphocyte infiltration was predominant. With HE staining, CD4- and CD8-positive T lymphocyte infiltration was stronger in areas where inflammatory cell infiltration was stronger (Fig. 7).

iv) IFN- $\gamma \mathrm{R} \alpha$

IFN- $\gamma \mathrm{R} \alpha$-positive cell infiltration was observed in the inflammatory cells surrounding the duct, and strong infiltration of IFN- $\gamma \mathrm{R} \alpha$ positive cells was observed as strong inflammatory cell infiltration was observed, as seen with CD4 and CD8 staining (Fig. 8).

v) CD11b

With CD11b staining, CD11b-positive cell infiltration was observed around pancreatic ducts in a diffuse manner in areas where inflammatory cell infiltration was strong. In the $1 \mathrm{mg}$ group, in which inflammatory cell infiltration was suppressed, the numbers of CD11b-positive cells were 

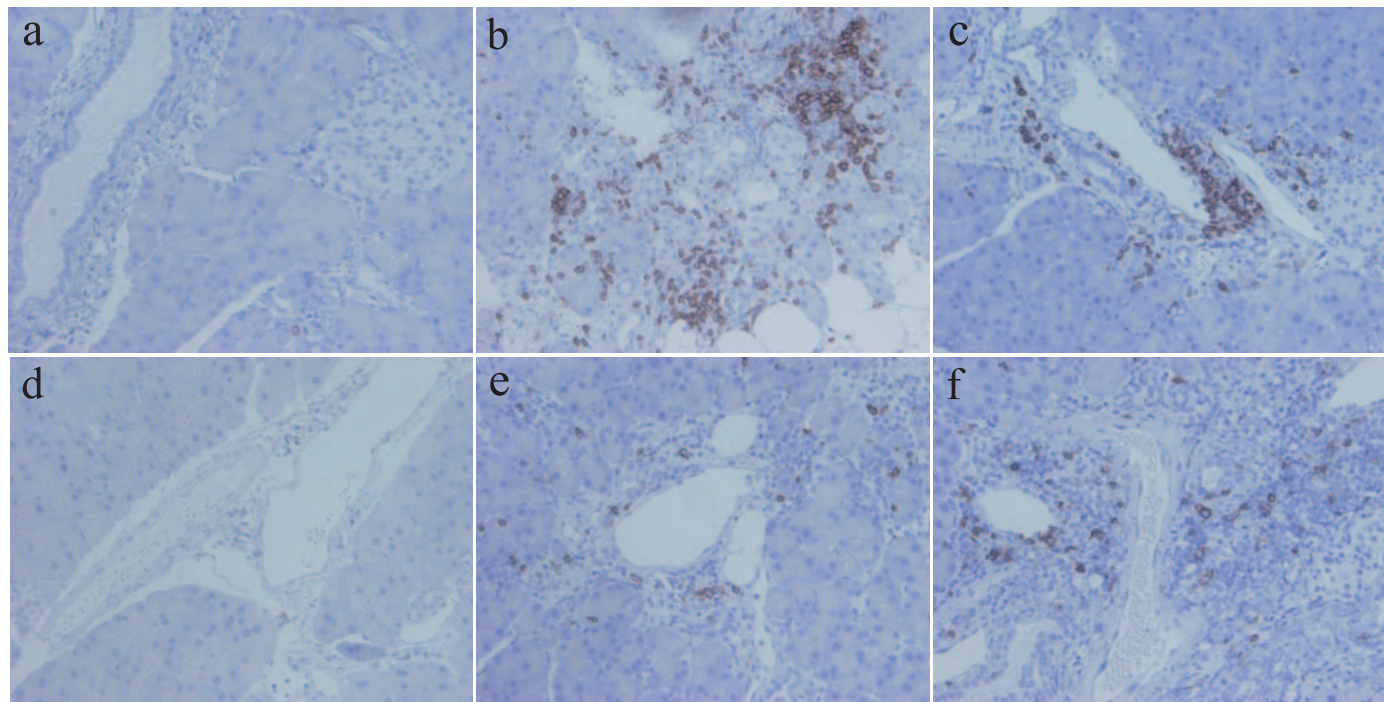

Fig. 7. CD4 and CD8 staining at 24 weeks of age. Inflammatory cell infiltration was dominated by CD4-positive cells in the pancreatitis group and the $2 \mathrm{mg}$ group. Inflammatory cell infiltration of CD4-positive and CD8-positive cells was suppressed in the $1 \mathrm{mg}$ group. a : 24 weeks of age, $1 \mathrm{mg}$ group, CD4 staining, $\times 200$ b : 24 weeks of age, $2 \mathrm{mg}$ group, CD4 staining, $\times 200$

c: 24 weeks of age, pancreatitis group, CD4 staining, $\times 200$

$\mathrm{d}: 24$ weeks of age, $1 \mathrm{mg}$ group, CD8 staining, $\times 200$

e : 24 weeks of age, $2 \mathrm{mg}$ group, CD8 staining, $\times 200$

f : 24 weeks of age, pancreatitis group, CD8 staining, $\times 200$
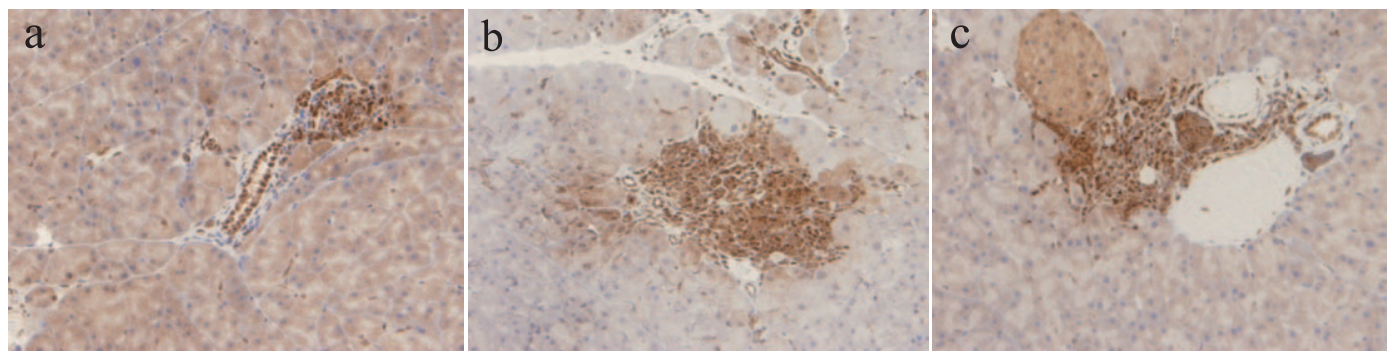

Fig. 8. IFN- $\gamma \mathrm{R} \alpha$ staining at 16 weeks of age. IFN- $\gamma \mathrm{R} \alpha$-positive cell infiltration was observed at sites where inflammatory cell infiltration was strong, and IFN- $\gamma \mathrm{R} \alpha$-positive cell infiltration was strongly observed in the $2 \mathrm{mg}$ and pancreatitis groups.

a : 16 weeks of age, $1 \mathrm{mg}$ group, IFN- $\gamma \mathrm{R} \alpha, \times 200$

$\mathrm{b}: 16$ weeks of age, $2 \mathrm{mg}$ group, IFN $-\gamma \mathrm{R} \alpha, \times 200$

c : 16 weeks of age, pancreatitis group, IFN- $\gamma \mathrm{R} \alpha, \times 200$

small. In the $2 \mathrm{mg}$ and pancreatitis groups, CD11b-positive cell infiltration was stronger than in the $1 \mathrm{mg}$ group. There was no significant difference in CD11b-positive cell infiltration between the $2 \mathrm{mg}$ group and the pancreatitis group (Fig. 9).

vi) Foxp3

Similar to CD11b staining, infiltration of Foxp3-positive cells was diffuse around the pancreatic ducts where inflammatory cell infiltration was strong. Foxp3-positive cell infiltration was observed in the $2 \mathrm{mg}$ group and pancreatitis group with strong inflammatory cell infiltration, but Foxp3positive cell infiltration was suppressed in the $1 \mathrm{mg}$ group (Fig. 10). 

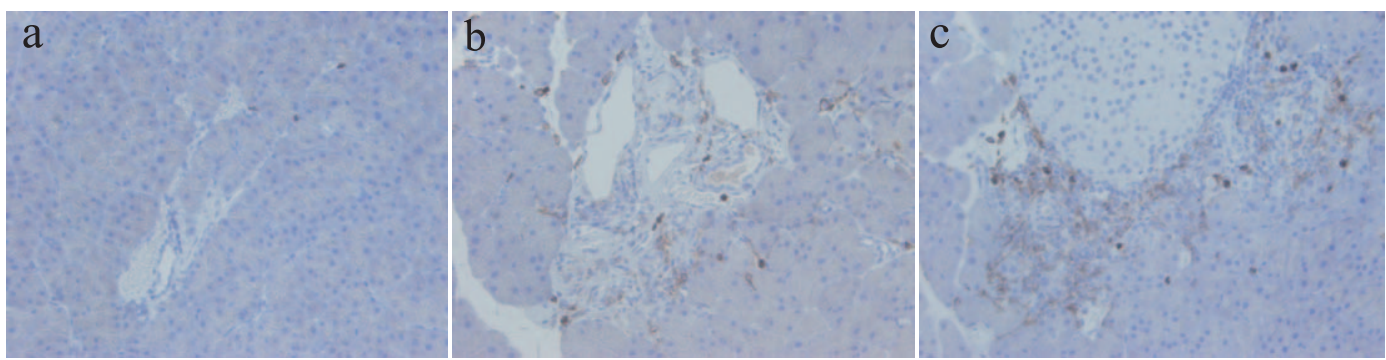

Fig. 9. CD11b staining at 16 weeks of age. There was no infiltration of CD11b-positive cells in the $1 \mathrm{mg}$ group, and CD11b-positive cell infiltration was observed around the duct in the $2 \mathrm{mg}$ and pancreatitis groups.

a : 16 weeks of age, $1 \mathrm{mg}$ group, CD11b, $\times 200$

$\mathrm{b}: 16$ weeks of age, $2 \mathrm{mg}$ group, CD11b, $\times 200$

c: 16 weeks of age, pancreatitis group, CD11b, $\times 200$
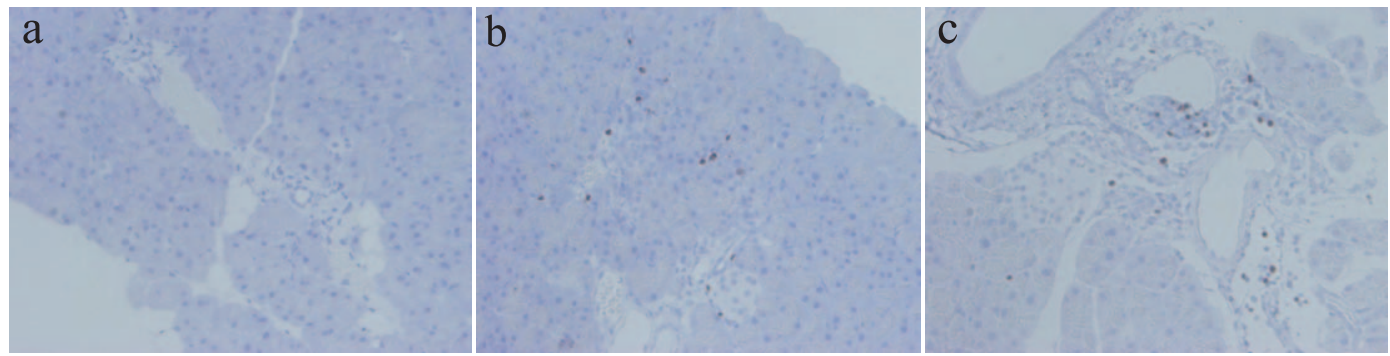

Fig. 10. Foxp3 staining at 16 weeks of age. Foxp3-positive cell infiltration was not observed in the $1 \mathrm{mg}$ group, but was observed around the duct in the $2 \mathrm{mg}$ and pancreatitis groups. a : 16 weeks of age, $1 \mathrm{mg}$ group, Foxp3, $\times 200$

b : 16 weeks of age, $2 \mathrm{mg}$ group, Foxp3, $\times 200$

c : 16 weeks of age, pancreatitis group, Foxp3, $\times 200$
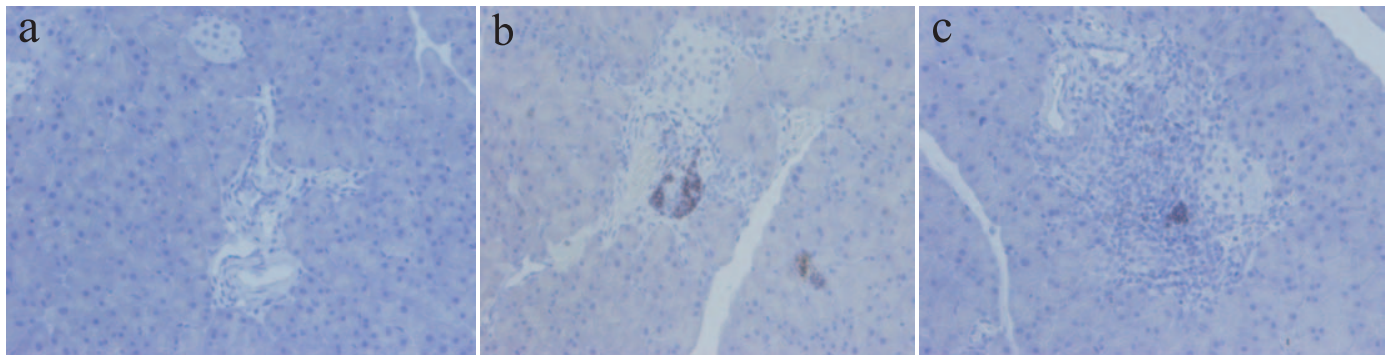

Fig. 11. CD45R staining at 16 weeks of age. CD45R-positive cells were not observed in the $1 \mathrm{mg}$ group, but were detected around the duct in the $2 \mathrm{mg}$ and pancreatitis groups.

a : 16 weeks of age, $1 \mathrm{mg}$ group, CD45R, $\times 200$

$\mathrm{b}: 16$ weeks of age, $2 \mathrm{mg}$ group, CD45R, $\times 200$

c : 16 weeks of age, pancreatitis group, CD45R, $\times 200$

\section{vii) $\mathrm{CD} 45 \mathrm{R}$}

With CD45R staining, CD45R-positive cell infiltration was observed in areas where inflammatory cell infiltration was strong. While CD11b-positive cells and Foxp3-positive cells were scattered diffusely around the pancreatic ducts, CD45R-positive cells appeared to cluster. CD45R-positive cells were found in the pancreatitis and $2 \mathrm{mg}$ groups, but not in the $1 \mathrm{mg}$ group (Fig. 11). 


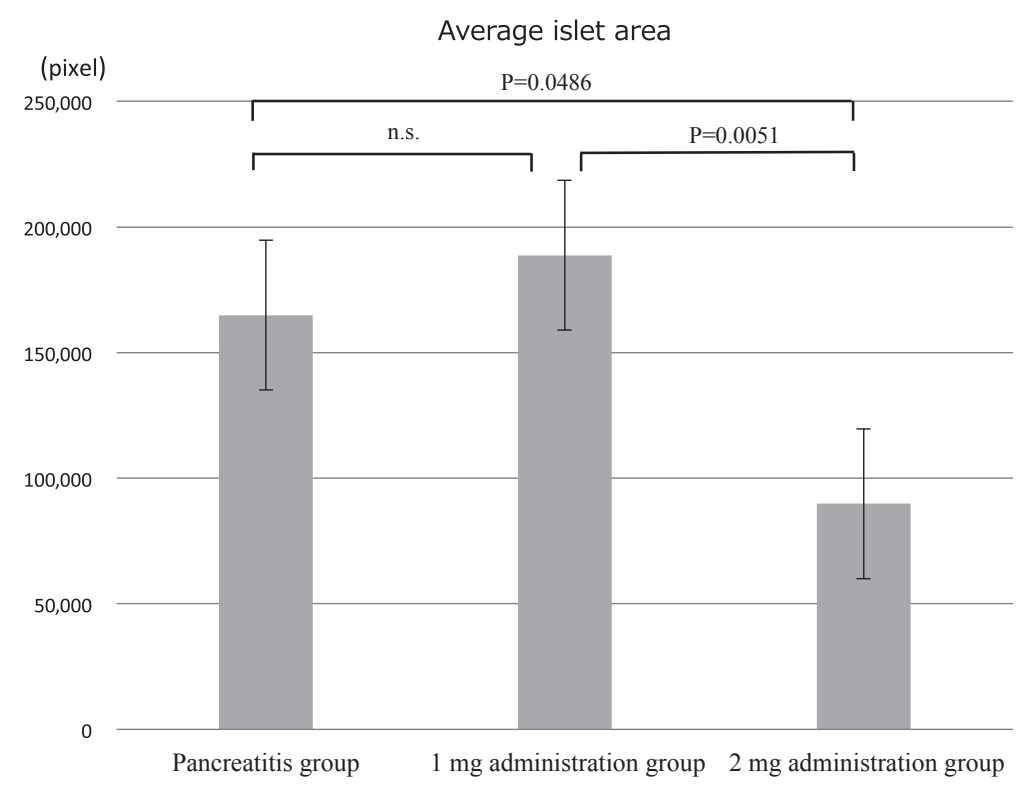

Fig. 12. Average islet area in each group. The pancreatic islet area in the $2 \mathrm{mg}$ group was significantly smaller than that in the pancreatitis group and in the $1 \mathrm{mg}$ group. There was no significant difference between the pancreatitis group and the $1 \mathrm{mg}$ group.

\section{Evaluation of endocrine function}

Evaluation of islet areas by insulin staining showed islet shrinkage and morphological changes in pancreatic islets in which inflammatory cell infiltration was observed. In contrast to the $1 \mathrm{mg}$ group, islet shrinkage and morphological changes were observed in the $2 \mathrm{mg}$ and pancreatitis groups with strong inflammatory cell infiltration, whereas islet size was relatively maintained in pancreatic islets with less inflammatory cell infiltration. Comparison of islet area revealed that the average islet area of the $2 \mathrm{mg}$ group was significantly smaller than that of the $1 \mathrm{mg}$ group $(\mathrm{P}=0.0051)$ and the pancreatitis group $(\mathrm{P}=0.0486)$. There was no significant difference in average islet area between the pancreatitis group and the $1 \mathrm{mg}$ group $(\mathrm{P}=0.4123$ ) (Fig. 12).

\section{Discussion}

Autoimmune pancreatitis is classified as an IgG4-related disease. Histologically, it is characterized by remarkable lymphocyte and plasma cell infiltration, IgG4-positive plasma cell infiltration, storiform fibrosis and tumor formation. Although adrenocortical hormone is generally effective for treatment of this disease, there are refractory cases and cases in which the therapeutic effect of adrenocortical hormone is poor. In addition, adverse effects due to long-term administration of adrenocortical hormone are problematic, even in cases where therapeutic effects are obtained. There are no definitive views on treatment for relapsed and refractory cases, but immunomodulators can be administered because they are considered to be effective. FK506 binds to FKBP (FK506 binding protein) in helper $\mathrm{T}$ cells, inhibits calcineurin, and suppresses the action of $\mathrm{T}$ cell activation factor. As a result, it inhibits the synthesis and secretion of various cytokines 
such as interleukins (typically IL-2) and leads to immunosuppression. In clinical practice, it is used for suppression of rejection during organ transplantation, intractable ulcerative colitis, rheumatoid arthritis, polymyositis, and interstitial pneumonia combined with dermatomyositis, and has a strong immunomodulatory effect. According to the 3rd nationwide AIP survey conducted in Japan, 5,745 patients had AIP in 2011, and more than $80 \%$ were treated with adrenocortical hormone $^{1)}$. Furthermore, 761 of 925 patients with AIP received steroid therapy ${ }^{1)}$. Among them, immunomodulatory drugs were used in 10 cases : azathioprine in four cases, cyclosporine in one case, methotrexate in one case, cyclophosphamide in one case, infliximab in one case, tacrolimus in one case, and the immunomodulatory drug was not specified in one case ${ }^{1)}$. In Europe and the United States, various immunomodulators have been examined, and case reports describing the use of azathioprine, mizoribine, methotrexate, cyclophosphamide and cyclosporin A have been published. However, it is still unclear which immunomodulatory agents are effective ${ }^{2-8)}$. In fact, rituximab is the most frequently administered in Europe and the United States, and there are reports showing efficacy in cases that do not respond to adrenocortical hormone. However, rituximab is not covered by insurance in $\operatorname{Japan}^{6)}$.

According to Ito et al, intravenous administration of FK506 and intraperitoneal administration of caerulein in rats with induced pancreatitis led to dose-dependent exacerbation of pancreatitis ${ }^{12)}$. In addition, it has been reported that administration of FK506 after organ transplantation has resulted in the development of pancreatitis ${ }^{13)}$. On the other hand, a study by Hashimoto et al, in which FK506 was subcutaneously administered to aly mice, showed an inhibitory effect on Bcl-2 protein, and a suppressing effect on the onset of pancreatitis due to $\mathrm{T}$ cell suppression ${ }^{14)}$. In our study, we investigated inhibitory or inducing effects of FK506 with $1 \mathrm{mg} / \mathrm{kg}$ or $2 \mathrm{mg} / \mathrm{kg}$ dosing on the onset of pancreatitis. In the $1 \mathrm{mg}$ group, the onset of pancreatitis was suppressed, and inflammatory cell infiltration remained mild compared to the pancreatitis group. However, in the $2 \mathrm{mg}$ group, inflammatory cell infiltration was observed from 16 weeks of age, which was earlier than in the pancreatitis group; in addition, the onset of pancreatitis could not be suppressed in the $2 \mathrm{mg}$ group, and the pancreatitis worsened. The mechanism of FK506 inducing toxicity and pancreatitis in the mouse and human pancreas has not been clarified. Although FK506 has a pancreatitis-suppressing effect at some doses, doses higher than the optimal dose may induce pancreatitis via pancreatic stimulation.

Various studies of AIP have been conducted using the aly mouse as a model. In our study, weight gain was significantly lower in the $2 \mathrm{mg}$ treatment group than in the pancreatitis group. In a previous study, more weight loss was observed as pancreatitis became more severe. However, in our study, while the body weight of each group was increased, the body weight in the pancreatitis group (in which pancreatitis developed) increased more than in the $1 \mathrm{mg}$ group (in which pancreatitis was suppressed). Tayama et al reported that FK506 administration induced hyperglycemia due to abnormality of glucose tolerance and that, as a consequence, the feeding center is suppressed, food intake decreases and body weight decreases ${ }^{9)}$. It has also been suggested that other factors such as gastrointestinal disturbance and decreased absorption of food due to a decrease in intestinal ATP are involved ${ }^{10,11)}$. Since we used a mouse model 
of pancreatitis in our study, we did not compare with animals that did not develop pancreatitis. However, we infer that the pharmacological effect of FK506 may have inhibited an increase in body weight. In addition, food intake was not measured in this study, so further investigation is necessary to examine the lower body weight gain in the $2 \mathrm{mg}$ group.

Immunohistochemical staining revealed that CD4-positive cells in the $2 \mathrm{mg}$ and pancreatitis groups dominated $\mathrm{T}$ lymphocyte cell infiltration. Hashimoto et al subcutaneously administered $2 \mathrm{mg} / \mathrm{kg}$ of FK506 to pancreatitis model mice ${ }^{14)}$. In our study, although we used the same dose of FK506, we administered it intraperitoneally to optimize accuracy of dosing. In general, blood concentrations of an administered drug are higher following intraperitoneal administration compared with subcutaneous administration. Therefore, we infer that the blood concentration of FK506 was higher in our study than the previous study that used subcutaneous administration.

FK506 overdose in humans has been reported to cause renal dysfunction or metabolic disorder, and it has been suggested that FK506 may induce pancreatitis in a dose-dependent manner ${ }^{15)}$. In clinical practice, immunomodulators are often administered in combination with steroids. According to international consensus on the treatment of AIP, administration of immunomodulators without steroids is less effective and should only be used when steroids or rituximab cannot be used. However, it is thought that a certain degree of suppression of inflammation can be obtained even with low-dose FK506 alone ${ }^{16)}$. As our study only assessed short-term use of FK506, further research on long-term use is needed.

Insulitis was analyzed to evaluate endocrine disorder, but pancreatic islets of Langerhans were found to have shrunk in the areas where there was strong inflammatory cell infiltration into the surrounding pancreatic acinar cells. The morphology of pancreatic islets of Langerhans was maintained in places where inflammatory cell infiltration was weak. As inflammation became stronger, infiltration of inflammatory cells into acinar cells as well as endocrine cells was observed. Inflammatory cell infiltration was suppressed in the $1 \mathrm{mg}$ group but, in the comparison of the pancreatic islet area, there was no significant difference from the pancreatitis group. From a histological standpoint, the suppression effect of FK506 on endocrine ability was not observed.

In a previous study, we observed inflammatory cell infiltration and vacuolation around the interlobular pancreatic duct in the AIP group from 16 weeks of age, pancreatic acinar cell loss from 24 weeks of age, and pancreatic acinar cell loss became prominent after 28 weeks of age. In addition to inflammatory cell infiltration, fibrosis has been observed ${ }^{17)}$. Our study collected data up to 24 weeks of age, and it is possible that endocrine function differences might have appeared in the pancreatitis and $1 \mathrm{mg}$ groups with longer-term use of FK506. Thus, we think that it is important to study long-term use, and to include both histological assessment and evaluation of endocrine function.

In our immunological evaluation, CD4-positive lymphocytes were dominant in the inflammatory cell infiltration in the pancreatitis group and $2 \mathrm{mg}$ group. IFN- $\gamma \mathrm{R} \alpha$-positive cell infiltration was observed at sites where inflammatory cell infiltration was strong. Although the pathogenesis of AIP is not yet fully understood, involvement of Th1 has been suggested to occur during early lesion formation. In the immunogenetic background, abnormality of the innate immune system, 
and acquired immune system shift to $\mathrm{Th} 2$, and regulatory $\mathrm{T}$ cells are thought to be involved in the pathogenesis ${ }^{18,19)}$. In pancreatic tissue of type 1 AIP, infiltration of regulatory $\mathrm{T}$ cells (Tregs) and IgG4-positive cells has been observed. It is thought that peripherally induced inducible co-stimulatory molecule (ICOS)-positive inducible memory Treg (i-Treg) is involved in IgG4 production, and ICOS-negative Treg is involved in fibrosis via TGF- $\beta^{20)}$. In the innate immune system, IgG4 production may be induced by BAFF (B-cell activating factor) produced from monocytes and basophils activated via TLR (toll-like receptors) and NOD (nucleotide-binding oligomerization domain) ${ }^{21,22)}$. In our study, infiltration of Foxp3-positive cells was suppressed in the $1 \mathrm{mg}$ group, in which inflammation was suppressed. Therefore, although administration of low-dose FK506 may have a suppressive effect on regulatory $\mathrm{T}$ cells, we believe that verification with long-term administration of FK506 is necessary to achieve an inhibitory effect on fibrosis associated with pancreatitis. Suppression of CD11b-positive cell infiltration was also observed, and natural immunity also showed a tendency to be inhibited by FK506. However, long-term administration of FK506 is likely to provide more information about the pathogenesis of pancreatitis.

In conclusion, in animal models of AIP, low-dose FK506 can be expected to be effective against exocrine disorders, but its effect on endocrine disorders is unclear. As pancreatitis symptoms tended to worsen at the higher dose, further research is required to determine the optimal dose. Since the endocrine disorder appeared at a later stage than previously reported, it is possible that the effect on endocrine disorder might be obtained by longer-term use. Therefore, additional research is necessary.

\section{Conflicts of interest disclosure}

We declare no potential conflicts of interest.

\section{References}

1) Kanno A, Masamune A, Okazaki K, et al. Nationwide epidemiological survey of autoimmune pancreatitis in Japan in 2011. Pancreas. 2015;44:535-539.

2) Masaki Y, Fujimoto S, Kawanami (Iwao) H, et al. How to diagnose and treat IgG4-related disease. J Kanazawa Med Univ. 2016;41:67-72. (in Japanese).

3) Khosroshahi A, Bloch DB, Deshpande V, et al. Rituximab therapy leads to rapid decline of serum IgG4 levels and prompt clinical improvement in IgG4-related systemic disease. Arthritis Rheum. 2010;62:1755-1762.

4) Khosroshahi A, Stone JH. Treatment approaches to IgG4-related systemic disease. Curr Opin Rheumatol. 2011; 23:67-71.

5) Topazian M, Witzig TE, Smyrk TC, et al. Rituximab therapy for refractory biliary strictures in immunoglobulin G4-associated cholangitis. Clin Gastroenterol Hepatol. 2008;6:364-366.

6) Khosroshahi A, Carruthers MN, Deshpande V, et al. Rituximab for the treatment of IgG4-related disease: lessons from 10 consecutive patients. Medicine (Baltimore). 2012;91:57-66.

7) Carruthers MN, Topazian MD, Khosroshahi A, et al. Rituximab for IgG4- related disease: a prospective, open-label trial. Ann Rheum Dis. 2015;74:1171-1177.

8) Raina A, Yadav D, Krasinskas AM, et al. Evaluation and management of autoimmune pancreatitis: experience at a large US center. Am J Gastroenterol. 2009;104:2295-2306. 
9) Tayama Y, Miyake K, Nagafuji T, et al. Influence of tacrolimus and ciprofloxacin on glucose metabolism. Yakugaku Zasshi. 2007;127:1883-1889. (in Japanese).

10) Hirano Y, Fujihira S, Ohara K, et al. Morphological and functional changes of islets of Langerhans in FK506treated rats. Transplantation. 1992;53:889-894.

11) Madsen KL, Yanchar NL, Sigalet DL, et al. FK506 increases permeability in rat intestine by inhibiting mitochondrial function. Gastroenterology. 1995;109:107-114.

12) Ito T, Kimura T, Furukawa M, et al. Protective effects of gabexate mesilate on acute pancreatitis induced by tacrolimus (FK-506) in rats in which the pancreas was stimulated by caerulein. J Gastroenterol. 1994;29:305-313.

13) Soran A, Shapiro R, Basar H, et al. Acute pancreatitis in renal transplant recipients under tacrolimus immunosuppression. Nagoya Med J. 1999;42:171-175.

14) Hashimoto $\mathrm{Y}$, Matsuoka N, Kawakami A, et al. Novel immunosuppressive effect of FK506 by augmentation of $\mathrm{T}$ cell apoptosis. Clin Exp Immunol. 2001;125:19-24.

15) O’Connor AD, Rusyniak, DE, Mowry J. Acute tacrolimus toxicity in a non-transplant patient. Clin Toxicol (Phila). 2008;46:838-840.

16) Okazaki K, Chari ST, Frulloni L. International consensus for the treatment of autoimmune pancreatitis. Pancreatology. 2017;17:1-6.

17) Sato Y, Yoshida H, Tanaka S, et al. Features of and mechanisms underlying insulitis in aly/aly male mice as an animal model of autoimmune pancreatitis: activation of CD11c (plus), CD4 (plus), and Th2 cells and predominant destruction of beta-cells. Showa Univ J Med Sci. 2012;24:139-153.

18) Okazaki K, Uchida K, Koyabu M, et al. Recent advances in the concept and diagnosis of autoimmune pancreatitis and IgG4-related disease. J Gastroenterol. 2011;46:277-288.

19) Uchida K, Okazaki K, Konishi Y, et al. Clinical analysis of autoimmune-related pancreatitis. Am J Gastroenterol. 2000;95:2788-2794.

20) Kusuda T, Uchida K, Miyoshi H, et al. Involvement of inducible costimulator-and interleukin 10-positive regulatory $\mathrm{T}$ cells in the development of IgG4-related autoimmune pancreatitis. Pancreas. 2011;40:1120-1130.

21) Watanabe T, Yamashita K, Fujikawa S, et al. Involvement of activation of toll-like receptors and nucleotide-binding oligomerization domain-like receptors in enhanced $\mathrm{IgG} 4$ responses in autoimmune pancreatitis. Arthritis Rheum. 2012;64:914-924.

22) Watanabe $\mathrm{T}$, Yamashita K, Sakurai T, et al. Toll-like receptor activation in basophils contributes to the development of IgG4-related disease. J Gastroenterol. 2013;48:247-253.

[Received December 27, 2017 : Accepted January 18, 2018] 